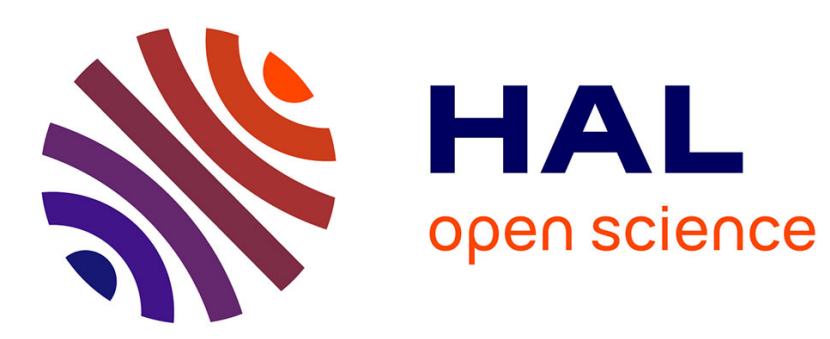

\title{
A methodology for cutting tool management through the integration of CAPP and scheduling
}

\author{
Amparo Meseguer Calas, F Gonzalez Contreras
}

\section{To cite this version:}

Amparo Meseguer Calas, F Gonzalez Contreras. A methodology for cutting tool management through the integration of CAPP and scheduling. International Journal of Production Research, 2008, 46 (06), pp.1685-1706. 10.1080/00207540600898049 . hal-00512939

\section{HAL Id: hal-00512939 \\ https://hal.science/hal-00512939}

Submitted on 1 Sep 2010

HAL is a multi-disciplinary open access archive for the deposit and dissemination of scientific research documents, whether they are published or not. The documents may come from teaching and research institutions in France or abroad, or from public or private research centers.
L'archive ouverte pluridisciplinaire HAL, est destinée au dépôt et à la diffusion de documents scientifiques de niveau recherche, publiés ou non, émanant des établissements d'enseignement et de recherche français ou étrangers, des laboratoires publics ou privés. 


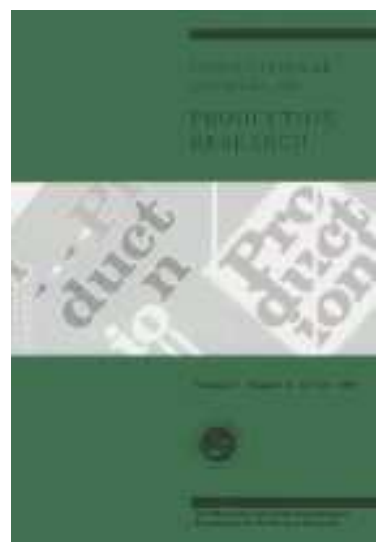

\section{A methodology for cutting tool management through the integration of CAPP and scheduling}

\begin{tabular}{|c|c|}
\hline Journal: & International Journal of Production Research \\
\hline Manuscript ID: & TPRS-2005-IJPR-0293.R2 \\
\hline Manuscript Type: & Original Manuscript \\
\hline $\begin{array}{r}\text { Date Submitted by the } \\
\text { Author: }\end{array}$ & 04-Jul-2006 \\
\hline Complete List of Authors: & $\begin{array}{l}\text { Meseguer Calas, Amparo; Polithecnical University of Valencia, } \\
\text { Mechanical Engineering } \\
\text { Gonzalez Contreras, F; Polytechnic University of Valencia, } \\
\text { Department of Mechanical Engineering }\end{array}$ \\
\hline Keywords: & $\begin{array}{l}\text { FLEXIBLE MANUFACTURING, SCHEDULING, CAPP, TOOL } \\
\text { MANAGEMENT }\end{array}$ \\
\hline Keywords (user): & \\
\hline
\end{tabular}

\section{$\diamond$ ScholarONE" \\ Manuscript Central}


Catchline International Journal of Production Research, Vol. X, No. X, Month 2004, xxx-xxx

\author{
Running heads \\ (verso) \\ A. Meseguer and F. Gonzalez \\ (recto) \\ A methodology for cutting tool management
}

\title{
A methodology for cutting tool management through the integration of CAPP and scheduling
}

\author{
A. MESEGUER $\dagger^{*}$, F. GONZALEZ $\dagger$ \\ $\dagger$ Department of Mechanical Engineering, Polytechnic University of Valencia, Camino de \\ Vera s/n 46022 Valencia, Spain \\ *Corresponding author. E-mail: amesegue@mcm.upv.es
}

Tool management is an important element in the efficiency of flexible manufacturing systems. This paper improves manufacturing flexibility through integrated computer aided process planning and scheduling with tool management. A new methodology for cutting tool management is introduced, based on the use of alternative tools. In the methodology proposed, computer aided process planning singles out all possible tool alternatives for each operation. The tool manager is designed to solve interferences between tool alternatives to make them compatible with scheduling. Interferences occur when the same tools are simultaneously needed in various machining operations. We propose a method to reduce tool alternatives. Thus, interferences disappear, and a collection of tool alternatives compatible with the scheduling of the system are obtained for machining operations. Tool 
management can use these sets of tools to plan tool changes that are necessary to face tool wear and to react to perturbations in the production system. To prove the response of our proposal, computational experiments are performed on randomly generated test problems.

Keywords: tool management, CAPP, scheduling, flexible manufacturing systems

\section{Introduction}

Flexible manufacturing systems (FMS) meet the needs of an evolving market in which products have shorter life cycles and limited delivery dates. However, their efficient operation is a difficult task and in many implementations their available capacity is underutilized. Tool management is an important issue in these systems, because tools are the most dynamic resource. Tool management should guarantee that the right tools are in the appropriate machines at the required time, to avoid unnecessary stoppages and delays (Gray 1993).

One of FMS planning problems is loading (Stecke, 1983). Loading can be defined as the allocation of the operations and the required tools to the individual machines taking the technological restrictions and productive resources of the system into consideration. To solve this problem is complex because each part consists of a set of operations that can be carried out by different machines, each operation can be machined by different tools and each tool can be involved in the machining of different operations. Tool magazine capacity constraints also apply, limiting the number of tools that can be loaded and making tool switching management necessary (Tang and Denardo, 1988). 
Loading problem has been widely dealt with in the literature (Grieco et al. 2001). Ho and Hsieh (2005) solve the loading problem of an FMS composed by several identical machines according to the tool movement policy. They propose an interactive part and tool assignment combining fuzzy c-means, simulated annealing and an optimal tool-assignment algorithm. Loading problem can be decomposed into part allocation and tool allocation problems. Tool allocation problem consists of assigning tools to operations, and most authors have used mathematical programming approaches to solve this problem, using variables 0-1 to represent tool requirements (Stecke 1983, Sarin and Chen 1987, Atan and Pandit 1996, Akturk 1999). Mendes et al. (2003) proposed integration of computer aided process planning with tool allocation through alternative process planning. They developed a mathematical model for the simultaneous determination of part mix, tool allocation and process plan selection in only one CNC machine centre. The problem is formulated only for a CNC machine centre, so it does not take into account the competition of the machines for the tools. To improve tool management, Matta et al. (2004) consider network part programs to adopt tool-sharing policies. They present dispatching rules to select the next operation to be performed in the machining centres, taking into account tools availability. However, they neither consider wearing and breaking of tools nor alternative tools for operations.

Although most studies deal with tool loading, there are also studies that solve the scheduling problem by considering tool management. Scheduling is one of the most important factors in the performance of FMS, since executing production orders implies the use of the same resources: tools, machines, transports, etc. (Ventura et al. 1990). Solving a scheduling problem at machine level without taking into consideration other resources such 
as tools could result into unfeasible scheduling. In that case, the same tools could be required by different machines at the same time, and the waiting time required for tool changes and transports could cause scheduling delays. Tool availability for each operation, tool magazine capacity, the use of alternative tools or the duplication of tools (Koo et al. 1998, Braglia and Zavanella 1999, Kim et al. 2003) and tool replacement due to wear (Sheikh 1999, Choi and Kim 2001) can influence scheduling success.

Traditionally, process planning and scheduling have been considered problems of a higher order, whilst tool management was pushed into the background under the assumption that tools were a less critical resource. Most of the studies that integrate tool management problem with scheduling, take into account not only machine resource, but tool resource as well to establish scheduling. Fathi and Barnette (2002) present heuristic procedures to solve scheduling in identical parallel machines. In their approach each machine has its proper set of tools to process all parts, so there are not tool shortages. They allocate the parts to the machines, sequence the parts on each machine and determine the tool-switching plan in every machine to minimize the makespan. Roh and Kim (1997) propose heuristics to solve loading and scheduling in several machines with a tool transporter. They consider two subproblems: part allocation and sequencing problem and tool loading problem. Although problems are related, they solved the problems separately, in an alternate and iterative way. In their approach they do not consider alternative tools in operation. Turkcan et al. (2003) proposes an algorithm to solve the non-identical parallel CNC machine scheduling problem, considering tool management. First, parts and tools are assigned to the machines and later, parts are scheduled on each machine. The parts are scheduled one at a time, 
depending on tool constraints, as the configuration of the tool magazine and the life-span of the tools.

This paper presents a suitable methodology for tool management integrated with computer aided process planning and scheduling. In our proposal, scheduling is established taking into account only machines resource, without considering tools resource. This is important, because machines resource is the most critical one. In order to reach a feasible scheduling, all alternative tools - which include both duplicated tools and other available tools that can carry out the operation - are considered within the wide possibilities offered by a generative CAPP (Gonzalez and Rosado, 2003, 2004). It permits coordinate in a flexible way tools resource with the scheduling established for the machines. This situation implies that many of the alternative tools considered are incompatible with the scheduling. This work proposes a method to solve this problem. After solving interferences between tools, each operation has alternative tools assigned to optimize the replacement of worn tools and to response to unexpected problems in the performance of the production system. Our approach, although solves the problem of tool management in an integral way (Roh and Kim 1997, Fathi and Barnette 2002, Turkcan et al. 2003), does not solve it in a similar way. Our strategy permits reduce the global problem to solve interferences among alternatives tools with scheduling.

This paper is organized as follows: Section 2 presents a general proposal for tool management integrated with scheduling and computer aided process planning; Section 3 deals with the problem of tool compatibility; Section 4 presents a numerical example; 
Section 5 presents computational results, and finally, concluding remarks are provided in Section 6.

\section{General proposal for tool management}

From a broad point of view, the purpose of tool management is to coordinate the use of the tools in the production system and to guarantee that the tools are available in the machines at the moment needed in order to execute the production orders. This is rather complex if one accepts the hypothesis of sharing tools among different machines. This article describes a methodology for managing cutting tools. The main characteristic of the proposal is its generality regarding tools and production systems. It is also flexible, and permits integration with the remaining production functions. It specifically integrates computer aided process planning and tool management, enabling production planning and scheduling without tool resources constraints. As computer aided process planning, production planning and scheduling are found at higher hierarchical levels, tool management must takes into consideration production plans, schedules and process plans (Figure 1). Functions are simply integrated through the use of exchange files in ASCII format. These files represent both process planning and scheduling.

'[Insert Figure 1 about here]'

The proposed tool manager is integrated with computer aided process planning. When choosing the machines, CAPP considers the capacities of its lower level resources such as ATC, slot availability, etc. CAPP and the methodology proposed in this work agree in offering alternative tools for each operation, which will allow the tool manager to organize tool use in accordance to scheduling. We will work under the assumption that only the most 
important resources have been considered for scheduling purposes, i.e. the machines. The higher the number of alternative tools considered, the higher the efficiency of this strategy. Therefore, CAPP must suggest every tool available for each operation, determining their working conditions. CAPP selects the cutting parts (inserts, drills, etc.) and the first adaptor supporting the cutting parts (insert holder, drill holder, etc.). The remaining adaptors that fit the tool to the machine must be chosen by the tool manager, coordinating the global use of this resource.

The proposed methodology establishes the necessary tasks for tool resource management and its execution order (Figure 2). Tool management is performed in periods of time called working periods. Each of these time periods usually includes several orders for each machine. Normally, the working periods can be made to coincide with periods corresponding to one or various working periods in the work shop.

'[Insert Figure 2 about here]'

The proposed methodology for tool management implies the sequential execution of four functions:

- Making tools compatible. Selecting all the alternative tools in each operation causes incompatibility or interference, since the interaction of tool resources is not taken into account. These interferences must be solved, making the tools compatible. The solution is to reduce the number of cutting tools alternatives in the operations. Seeking compatibility is a complex problem, due to the large number of interferences that arise and to the overlapping that occurs among them. After 
determining compatibility, each operation has several alternative tools assigned to it with no interference among them, which will facilitate tool management.

- Determining adaptors. Once tool alternatives are made compatible, all possible tools that can be used in each operation are available. In order to fit the tools in the machines, adaptors such as ISO cones, VDI shanks, etc. are necessary. This function is in charge of distributing these adaptors among the different alternative tools. In case of adaptor shortage, some alternative tools need to be eliminated according to their degree of importance, which will be determined by criteria such as for example pricing.

- Managing cutting parts. Once the tools to be used in each operation have been decided, the remaining tool management functions must coordinate tool usage. The edges of the cutting parts lose their cutting capacity through use and need to be replaced and the tool adjusted. The planning for such replacements and adjustments need to be organized by tool management to minimize production stoppages. Therefore, this function is mainly based on the alternative tools available for the operations.

- Coordinating tool flow. Tools are shared among different machines, just as the adaptors are shared among different tools. This function manages the flow of tools and adaptors. It also decides and coordinates how long the tools stay in the machines, and their transfer to other machines or to the central tool store. At the same time, it decides which tools are to be dismounted in order to mount others. 
This function also coordinates the capacity of tool resource taking into account the tool requirements in the machines, and the capacity of the tool magazines.

Making tools compatible is the most complex and important function for the implementation of the methodology proposed and thus, the next section will deal with it in detail.

\section{Making tools compatible}

The main objective of this function is to reduce the alternative tools for every operation, avoiding incompatibilities among them. This way, several alternative tools will be available, which will facilitate the management of this resource.

The problem of interferences is very serious and complex, since all the alternative tools have been considered in each operation as initial alternatives. Methods such as enumeration are able to find the optimum solution in high computational times. These types of problems can be solved by heuristic methods, which can obtain acceptable solutions in a reasonable amount of time. Our proposal consists of solving interferences one by one through an iterative procedure described below.

After solving each of the interferences, tools are eliminated from some of the operations, causing a decreasing number of alternative tools in the consecutive compatibilization processes. This changes the state of the alternative tools, and thus the problem becomes a new one after each compatibilization process is carried out. This iterative process finishes when there are no longer interferences during the working period. The result of the compatibilization is a set of alternative tools that are compatible for each operation. 
Although the interferences are solved individually, there are two global objectives in the search for a solution through the successive compatibilities. The main objective consists of making sure that the problem of compatibilization has a solution. This solution is obtained when there is at least one compatible alternative tool for each operation. The second objective is to get a uniform distribution of the tools, taking into consideration the needs of each operation. These needs are evaluated by the number of cutting parts consumed.

The problem is solved with consecutive iterations. There are three steps in each of the iterations that have to be carried out: analysing interferences, selecting interferences to make compatible and solving interferences.

\subsection{Analysing interferences}

This function identifies and analyses the interferences of each tool in order to know their importance in the working period, characterising each of the interferences through indexes. Basic interferences can be classified into two types: interference among machines or interference within a production order. In practice, an interference is the combination of several types of interferences.

Basic interference in orders pertaining to different machines is produced when several machines require the same tool, in orders that overlap in time. These interferences also arise when it is not possible to transfer and prepare the tools between orders, even when there is no overlap in time.

Basic interference within a production order occurs when several operations require the same tool, but different cutting parts. One example of this is the case of the same drill holder to mount different drills in different operations pertaining to the same order. In such 
a case, if several tools (drill holders) are not available, it is necessary to change the cutting part of the tool to execute the different operations. This would be repeated in the machining of each part in the batch. Obviously, these interferences are not as critical as those that occur among machines because, in the case of a tool shortage, the operations with interference within the order can share the same tools.

Figure 3 shows a schedule through a Gantt chart in a production system comprising three machines. In each order, the operations are shown with all of the tool alternatives specified by CAPP. Tools are classified by numbers and cutting parts by letters. A detailed explanation is also given for operations and alternative tools in machine 1 (Tables 1 and 2). '[Insert Table 1 about here]'

'[Insert Table 2 about here]'

'[Insert Figure 3 about here]'

Once the interferences are identified, the relative importance of each of them is evaluated to establish which one will be compatibilized in the first place. The interferences are analysed individually through indexes that evaluate different aspects of the interference. The indexes considered are as follows:

- Machines that require the tool (MRT). Number of different machines that require the tool simultaneously in the interference.

- Maximum petitions of the tool by the machine (MPTM). Each machine involved in the interference requires the tool a number of times in its different orders. Obviously, only the orders pertaining to the interference are considered. This need of the tool represents the serial use of the tool, without 
changing machine. This index takes the maximum value of this characteristic from among the machines involved in the interference.

- Tool cost (TC). Average tool cost in all of the operations that contain the tool that causes the interference, taking into account the number of cutting parts necessaries. This average cost permits comparing it with the other tools.

- Average number of tool alternatives in interference operations (ANTA). Average value of the tool alternatives in the interference operations that contain the tool that causes the interference. This index evaluates the volume of the alternative tools available.

- Minimum number of tool alternatives in interference operations (MNTA). Minimum value of tool alternatives in the interference operations that contain the tool causing the interference. This index evaluates the existence of operations with few alternatives.

Each of these indexes takes different information into account. Thus, the values of each index can vary greatly. In order to include all of them in one index to compare the interferences, the indexes must be normalized. Normalization is carried out to ensure that the value of each index is comprised in the interval [0-1]. MRT, MPTM and TC indexes are divided between the maximum values of each index in the whole of all interferences. For example, considering that in the interference of a tool the index MRT has a value of 2, if the maximum value of that index in the whole of the interferences is 4 , the normalized index for the tool interference adopts the value of 0,5 . The minimum values of ANTA and 
MNTA indexes in the whole of all the interferences are divided between the values of ANTA and MNTA in each interference. Therefore, I1, I2, I3, I4 and I5 correspond to the normalized value of the indexes MRT, MPTM, TC, ANTA and MNTA. Table 3 shows these indexes evaluated for example presented in figure 3. Tool 1 has the following costs: 2 in operation $1,3.5$ in operation $7,2.6$ in operation 10 and 0.7 in operation 13 . Therefore, TC index for tool 1 is 2.2 .

'[Insert Table 3 about here]'

\subsection{Selecting interferences to make compatible}

The solution to the problem of compatibility depends on the order in which the interferences are solved. In order to guarantee a good solution to the problem through a step-by-step method, the most restrictive interference needs to be compatibilized first. The most restrictive interference is selected by using the indexes that characterize the interferences, which determine the order in which the ensuing compatibilization processes should be made.

The index MNTA with value equal to the unit indicates that the interference has one or more operations in which the only alternative tool is the one that causes the interference. In this case, the problem can be solved only if the tool is assigned to that operation, removing it as an alternative for the rest of the operations of the interference that are incompatible with this assignation. Therefore, the interferences that present a unit value in this index are solved first, since they correspond to critical cases. Thus, in these cases, the value of the other indexes is not taken into consideration. These situations can occur in the last compatibilization processes when fewer alternative tools are available (figure 4). 


\section{'[Insert Figure 4 about here]'}

If there are no interferences in which the value of the index MNTA equals a unit, the next interference to make compatible will be chosen by considering all the characterization indexes. To do this, the normalized indexes values of the interferences are combined in a weighted linear function called characterization function $(F)$. This function evaluates the different aspects of the interference together for selecting the interference to make compatible. The weight of each index is referred to as $\mathrm{w}_{\mathrm{i}}$, and its value is comprised in the interval $[0,1]$.

$$
F=w_{1} * I 1+w_{2} * I 2+w_{3} * I 3+w_{4} * I 4+w_{5} * I 5
$$

Through the use of the coefficients $\mathrm{w}_{\mathrm{i}}$, more or less relative importance can be given to the different issues considered. Due to the nature of the problem, indexes I1 and I5 should be considered the most important because they represent the most restrictive aspects of the interference. At the same time, remainders indexes must be considered, although with less relative importance. These remainders indexes do not represent critical aspects of the interference, but they need to be considered at equality of indexes I1 and I5. Evidently, as the main objective is to find a solution to the problem, index $\mathrm{I} 3$, related to cost, is less important than the others.

A study has been generated to determine the value of the weights. It has been observed that the suitable weights depend on the characteristics of the initial problem. Specifically, they depend on the number of the tools and their distribution among the operations. To establish a general recommendation, we have considered different initial problems with different tool 
distributions. A computational study has been developed with these problems, to find appropriate weights that generate good solutions in them.

Finally proposed weights are: $\mathrm{w}_{1}=0.3 ; \mathrm{w}_{2}=0.15 ; \mathrm{w}_{3}=0.1 ; \mathrm{w}_{4}=0.15 ; \mathrm{w}_{5}=0.3$.

\subsection{Solving interferences}

This function solves each of the interferences selected by the previous function. Interferences with the unit as MNTA have a single solution. If these cases cannot be solved it will be because there are operations that are left without any tools. In this case, there is no solution to the compatibility problem. The remaining interferences have a more complicated solution since there are several alternative solutions. The procedure to solve these interferences consists of three steps: determining compatibility solutions, characterization of compatibility solutions and selection of the compatibility solution.

3.3.1 Determining compatibility solutions. Compatibility solutions are the possible solutions to incompatibility problems in interferences. Each compatibility solution is a set of operations in which the tool can remain to avoid interference. Compatibility solution alternatives are generated through an algorithm that determines the possible solutions through combinatorial analysis. The algorithm generates all possible combinations without interferences. To achieve it, the times of initiation and finalisation of the orders as well as the estimated time involved in transporting the tools, are taken into consideration. In example presented in figure 3, possible compatibility solutions for interference of tool 3 are: $\mathrm{O} 1-\mathrm{O} 4 ; \mathrm{O} 3-\mathrm{O} 4$ and $\mathrm{O} 5$.

3.3.2 Characterization of compatibility solutions. Once the different possible compatibility solutions are known, a decision has to be taken concerning which one will be 
used to solve the interference. In order to do so, different aspects should be analysed. The data required to analyse the compatibility solutions has been structured into three groups:

- Data concerning the orders involved in the interference.

- Data concerning the operations involved in the interference.

- Data concerning compatibility solutions.

3.3.2.1 Data concerning the orders involved in the interference. This data is analysed through an index referred to as A. This index is defined for each of the orders of the interference. It is a boolean index with a value of 0 or 1 . For each operation involved in the interference, this index evaluates the existence of tools already compatible in another operation of the same order and initially taken as alternatives in the operation considered. When this is the case in all the operations of the order involved in the interference, the value of this index is 0 . If not, its value is 1 .

This index detects the possibility of using a tool already compatible in another operation of the same order that was also an initial alternative in the operation considered. This would involve changes in the cutting part of the tool, but would be an initial solution.

\subsubsection{Data concerning the operations involved in the interference. The} characterization of the operations involved in the interference is carried out through indexes $\mathrm{B}$ and $\mathrm{C}$. Index $\mathrm{B}$ indicates the existence of compatible tools in the operation. It is a boolean index with a value of 0 or 1 . This index evaluates, for each of the operations involved, whether other previously compatible tools that might serve as alternatives in the operation, exist or not. If they do exist, the index is 0 . If they do not, it is 1 . The 
information obtained through index B is directly related to the degree of necessity that each operation has of the tool.

Index $\mathrm{C}$ represents the relation between the number of cutting parts that are necessary in the operation and the compatibilized tool alternatives in the operation. This index is evaluated for each of the operations involved in the interference. This index evaluates the need of more alternatives for each operation when, due to the estimated cutting times, there is a greater use of cutting parts than in the other operations.

Index A and B represent the first goal of tool compatibilization, which consists of obtaining a basic solution for the problem. These indexes indicate the need for compatible tools. Index $\mathrm{C}$ evaluates the operations to ensure the distribution of alternative tools according to the requirements of the operations. Alternative tools are thus more numerous for operations with higher global cutting time.

3.3.2.3 Data concerning compatibility solutions. All data on possible compatibility solutions need to be taken into account to find the best possible option, and therefore, indexes $\mathrm{A}, \mathrm{B}$ and $\mathrm{C}$ need to be considered together with additional data such as tool transports and critical cases.

In order to consider indexes $\mathrm{A}, \mathrm{B}$ and $\mathrm{C}$ for compatibility solutions, the sum or the maximum value of each index is obtained for each of the compatibility solutions. Index $\bar{A}$ is evaluated as the sum of index $\mathrm{A}$ in all of the orders involved in the compatibility solution. Index $\bar{B}$ is calculated as the sum of index $\mathrm{B}$ in all of the operations involved in the interference and contained in the compatibility solution. Finally index $\bar{C}$ is calculated 
as the maximum value of index $\mathrm{C}$ in all the operations involved in the interference and contained in the compatibility solution.

A key aspect of tool management is transporting the tools among the machines and from the tool central store to the machines. Since all compatibility solutions could need tool transportation, transport needs to be taken into account together with tool location before and after the interference. Figure 5 shows the evaluation of index $\bar{A}$ and required transports for example presented in figure 3 . In the first step, interference related to tool 3 will be solved, being tool 3 located at machine 3 at the beginning of the working period.

'[Insert Figure 5 about here]'

We previously mentioned the problems regarding interferences in which there are critical cases. Critical cases usually arise during the successive iterations carried out to solve the interferences. This is due to the progressive decrease of alternatives in the operations. The appearance of critical cases can be foreseen by studying the compatibility solutions. Thus, each compatibility solution is analysed to evaluate the number of critical cases found for each of them and avoid them beforehand

3.3.3 Selection of the compatibility solution. Compatibility solutions are chosen by taking into account the following data: $\bar{A}, \bar{B}, \bar{C}$, number of critical cases and number of transports.

The optimal compatibility solution is selected through the algorithm shown in figure 6 . The algorithm considers, in compatibility solutions, index $\bar{A}$ first, and then index $\bar{B}$, thus giving priority to the goal of having at least one tool compatible for each operation. When the value of both index $\bar{A}$ and $\bar{B}$ is zero, index $\bar{C}$ is taken into consideration to distribute 
the different tool alternatives among the operations that most need cutting elements. If the value of index $\bar{A}$ or index $\bar{B}$ is different of zero, compatibility solutions are selected giving priority to those ones that avoid generation of critical cases. When the value of both index $\bar{A}$ and $\bar{B}$ is zero there is not possibility to generate critical cases.

\section{'[Insert Figure 6 about here]'}

There are three basic rules to select compatibility solution. First, we select the compatibility solution with the greatest value of index $\bar{A}$. If there are some compatibility solutions in these conditions, the one with minimum number of transports is selected. If number of transports is the same, index $\bar{B}$ first, and index $\bar{C}$, if necessary, are evaluate to choose the compatibility solution. Secondly, when index $\bar{A}$ is zero, we select compatibility solution with the greatest value of index $\bar{B}$. If there are some compatibility solutions in these conditions, the one with minimum number of transports is selected. If number of transports is the same, index $\bar{C}$ is evaluated to select the compatibility solution. Thirdly, when both index $\bar{A}$ and $\bar{B}$ is zero, we select compatibility solution with the greatest value of index $\bar{C}$. If there are some compatibility solutions in these conditions, the one with minimum number of transports is selected. To select the compatibility solution, transports are considered afterwards evaluating indexes $\bar{A}, \bar{B}$ and $\bar{C}$. In this way, minimising transports has been considered as a secondary objective in the algorithm proposed.

\section{Numerical example}

A prototype tool manager according to the methodology proposed has been implemented. To date, our work has been mainly focussed on the function of making tools compatible. In the simulations that we have already carried out, we parted from the process plans for the 
parts we aimed to produce. These plans offer tool alternatives for each of the machining operations involved. Once the process planning and the batch sizes are known, the tool manager carries out a compatibilization of the alternative tools according to the scheduling established.

In this section a numerical example of the proposed methodology is presented. The following example presents a family of pieces that require lathes, millings and grinding machines for their machining operations. To keep things simple, only the milling section will be considered for making tools compatible. We will specifically consider four vertical milling machines of similar characteristics.

Table 4 shows the tools available in the system and their most relevant characteristics. Thirteen different pieces have been considered and their corresponding process plans have been elaborated. Table 5 presents, for each piece, the batching size (B.S.), the necessary orders, a brief description of the operations that should be carried out in each of them and the alternative tools.

'[Insert Table 4 about here]'

'[Insert Table 5 about here]'

A scheduling based on the due dates and the characteristics of each batch is established for these pieces. The scheduling is shown through a Gantt chart in figure 7. Times are in minutes.

'[Insert Figure 7 about here]' 
The compatibilization process starts by identifying the interferences caused by each tool. Tool transport time between machines is established in 5 minutes. There are 63 interferences caused by 56 tools. Once the interferences are identified, they are analysed through the indexes proposed, and the first interference to make compatible is then decided. Interference of tool 6 is assessed as the most restrictive and is therefore chosen as the first to make compatible. Clearly, these data belong to the first iteration of the problem and will change in each of the iterations.

Once the interference to make compatible (interference 6) has been selected, the compatibility solutions are determined - the one deemed most appropriate should be chosen. At the beginning of the working period, tools are located as shown in table 6 . The compatibility solutions specify the operations in which the tool will remain as a compatible option while being removed from the rest (figure 8).

'[Insert Table 6 about here]'

'[Insert Figure 8 about here]'

A new problem is generated once the interference is solved, since the tool alternatives in the operations have changed. Thus, the process stated is followed iteratively until all of the interferences are solved. Table 7 shows the final situation of the tools after compatibilization. There are some operations with more tool alternatives than others because of two reasons. More tools are assigned to operations that require more cutting elements and operations with few interferences do not loose their initial tool alternatives. The average number of tool alternatives per operation, which was 6.42 before 
compatibilization, is now 2.69 , since making compatible the resource involves a logical decrease of alternatives.

'[Insert Table 7 about here]'

\section{Computational results}

To evaluate the performance of the proposed algorithm, a computational study is presented. Algorithm was coded in the $\mathrm{C}++$ language and problems were solved on a personal computer with a Pentium IV processor operating at $3.2 \mathrm{GHz}$ clock speed. There are five primary experimental factors that affect the efficiency of the algorithm suggested in this paper: number of machines, number of orders per machine, number of operations per order, tool types and number of alternative tools per operation (Table 8). The experimental design is a $2^{5}$ full-factorial design with two levels each. For the experiments, five problems were generated for each of all combinations, producing 160 different randomly runs.

'[Insert Table 8 about here]'

Computational time depends on the number and size of the interferences generated in every experiment. This time increases, as values of experimental factors as well increases. Experimental factors have been selected to generate a great number of interferences in every experiment, in order to prove the response of the algorithm.

The number of machines and the number of orders per machine affect the global size of the problem. If the number of orders per machine increases, the number of different compatibility solutions to evaluate increases, because there are more combinations among the orders to form the compatibility solutions. The number of operations per order affects 
the number of interferences within a production order. As this factor increases there are more probability to find interferences within a production order. Tool types affect the number of different tools introduced in the system. As this number increases, problem is enlarged. The number of alternative tools per operation affects the number of interferences to be solved.

The other variables of the problem have been generated as follows. Working period has a value of 1000. The time for tool transport among machines and between machines and the tool central store is selected from $\mathrm{UN} \sim[5,9]$. Tools have been placed randomly in the tool magazine of the machines and in the tool central store at the beginning of the working period. The tool cost has been generated randomly. Cost of every tool alternative depends on both the tool and the machining operation. Therefore, these factors have been taking into account to generate randomly costs in a coherent way.

Table 9 shows average computational times for the different experiments generated. All these values are less than 1 minute.

'[Insert Table 9 about here]'

\section{Conclusions}

This paper presents a new methodology for the tool management problem based on the use of alternative tools. The main characteristic of the proposal is the integration of tool management with CAPP and scheduling. The strategy followed takes advantage of the capacity of CAPP to generate all alternative tools for every operation. With this data, the tool manager is able to solve alternative tool conflicts to obtain a set of alternatives 
compatible with scheduling. Thus, scheduling is free of tool resource restrictions. Our proposed procedure requires a CAPP system, but nowadays there is a scarce industrial implementation of CAPP systems. Also, the CAPP systems required need to be capable of proposing alternative tools for each of the operations. Variant CAPP systems are not oriented towards that goal, which restricts the proposal to generative CAPP systems.

The proposed methodology does not guarantee finding the optimal solution, although a good solution can be obtained. The proposed methodology to solve interferences is based on a procedure to distribute tools among machining operations depending on the needs of tools of the operation. As decisions about tool transport have been relegated at the end in the proposal, the obtained solution could be improved by decreasing number of transports in a posterior step. In this case, a global analysis of duplicated tools is required in order to relocate the tools among the operations. After making tools compatible, there are alternative tools for the different operations, providing more possibilities for tool management. One of the main advantages is being able to use the different tools as alternatives in the same operation, without needing to resort to duplicated tools. This enables the tool manager to reduce non-producing time and to react before disruptions arise during production. Once tool alternatives are compatible, the procedure can be carried out based on different objectives: minimising tool transportation, minimising the number of tools being used, etc. The methodology proposed has been checked with test problems to verify its performance and limitations. 


\section{References}

Akturk, M. S., An exact tool allocation approach for CNC machines. International Journal of Computer Integrated Manufacturing, 1999, 12, 129-140.

Atan, T. S. and Pandit, R., Auxiliary tool allocation in flexible manufacturing systems. European Journal of Operational Research, 1996, 89, 642-659.

Braglia, M. and Zavanella L., Experiences and issues in evaluating tool requirement using genetic algorithms. Production Planning and Control, 1999, 10, 340-358.

Choi, Y.-C. and Kim, Y-D., Tool replacement policies for a machining centre producing multiple types of products with distinct due dates. International Journal of Production Research, 2001, 39, 907-921.

Fathi, Y. and Barnette, K. W., Heuristic procedures for the parallel machine problem with tool switches. International Journal of Production Research, 2002, 40, 151-164.

Gonzalez, F. and Rosado, P., General and flexible methodology and architecture for CAPP: GF- CAPP system. International Journal of Production Research, 2003, 41, 2643-2662.

Gonzalez, F. and Rosado, P., General information model for representing machining features in CAPP systems. International Journal of Production Research, 2004, 42, 1815-1843.

Gray, A. E., Seidman, A. and Stecke, K. E., A synthesis of decisions models for tool management in automated manufacturing. Management Science, 1993, 39, 549-567.

Grieco, A., Semeraro, Q. and Tolio, T., A review of different approaches to the FMS loading problem. International Journal of Flexible Manufacturing Systems, 2001, 13, 361-384.

Ho, Y.-C. and Hsieh, H.-W, A part-and-tool assignment method for the workload balance between machines and the minimisation of tool shortage occurrences in a FMS. International Journal of Production Research, 2005, 43, 1831-1860.

Kim, Y.-D., Lee, G.-C., Lim, S.-K. and Choi, S.-K., Tool requirements planning in a flexible manufacturing system: minimizing tool costs subject to a makespan constraint. International Journal of Production Research, 2003, 41, 3339-3357.

Koo, P.-H., Tanchoco, J. M. A. and Talavage, J. J., Estimation of tool requirements in single-stage multimachine systems. International Journal of Production Research, 1998, 36, 1699-1713.

Matta, A., Tolio, T. and Tontini, F., Tool management in flexible manufacturing systems with network part program. International Journal of Production Research, 2004, 42, 3707-3730.

Mendes, M., Mikhailov, M. D. and Qassim, R. Y., A mixed-integer linear programming model for part mix, tool allocation, and process plan selection in CNC machining centres. International Journal of Machine Tools \& Manufacture, 2003, 43, $1179-1184$. 
Roh, H. K. and Kim, Y. D., Due-date based loading and scheduling methods for a flexible manufacturing system with an automatic tool transporter. International Journal of Production Research, 1997, 35, 2989-3003.

Sarin, S. C. and Chen, C. S., The machine loading and tool allocation problem in a flexible manufacturing system, International Journal of Production Research, 1987, 25, 1081-1094.

Sheikh, A. K., Optimal tool replacement and resetting strategies in automated manufacturing systems, International Journal of Production Research, 1999, 37, 917-937.

Stecke, K. E., Formulation and solution of nonlinear integer production planning problems for flexible manufacturing systems. Management Science, 1983, 29, 273-288.

Tang, C. S. and Denardo, E. V., Models arising from a flexible manufacturing machine, Part I: Minimization of the number of tool switches. Operations Research, 1988, 36, 767-777.

Turkcan, A., Akturk M. S. and Storer, S. H., Non-identical parallel CNC machine scheduling. International Journal of Production Research, 2003, 41, 2143-2168.

Ventura, J. A., Chen, F. F. and Wu, C-H., Grouping parts and tools in FMS production planning. International Journal of Production Research, 1990, 28, 1039-1056 


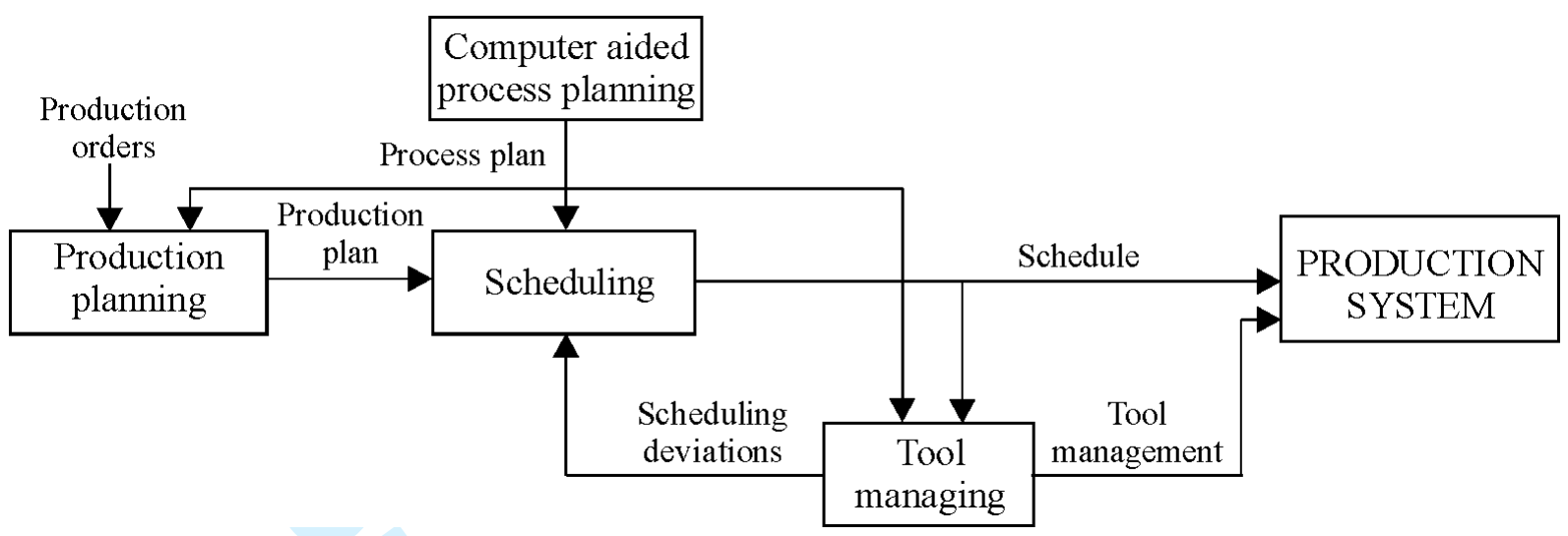

Figure 1. Tool management integration 


\section{TOOL MANAGING}

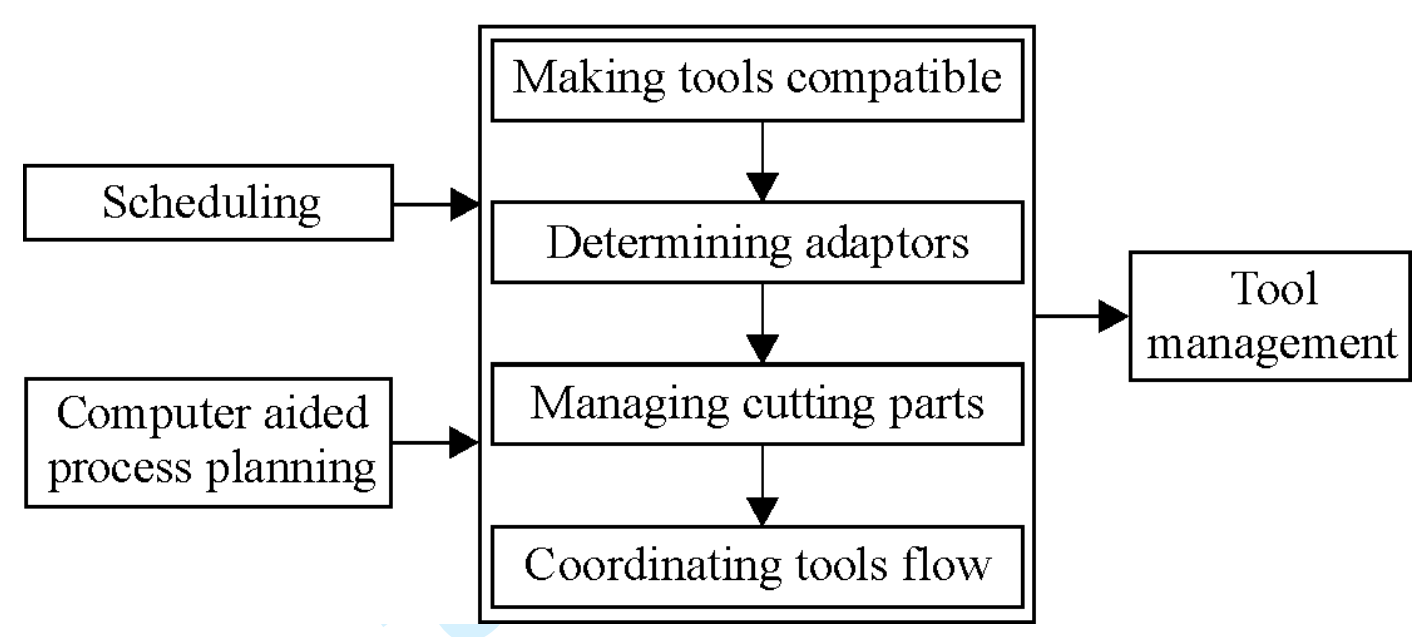

Figure 2. Proposed methodology for tool management 


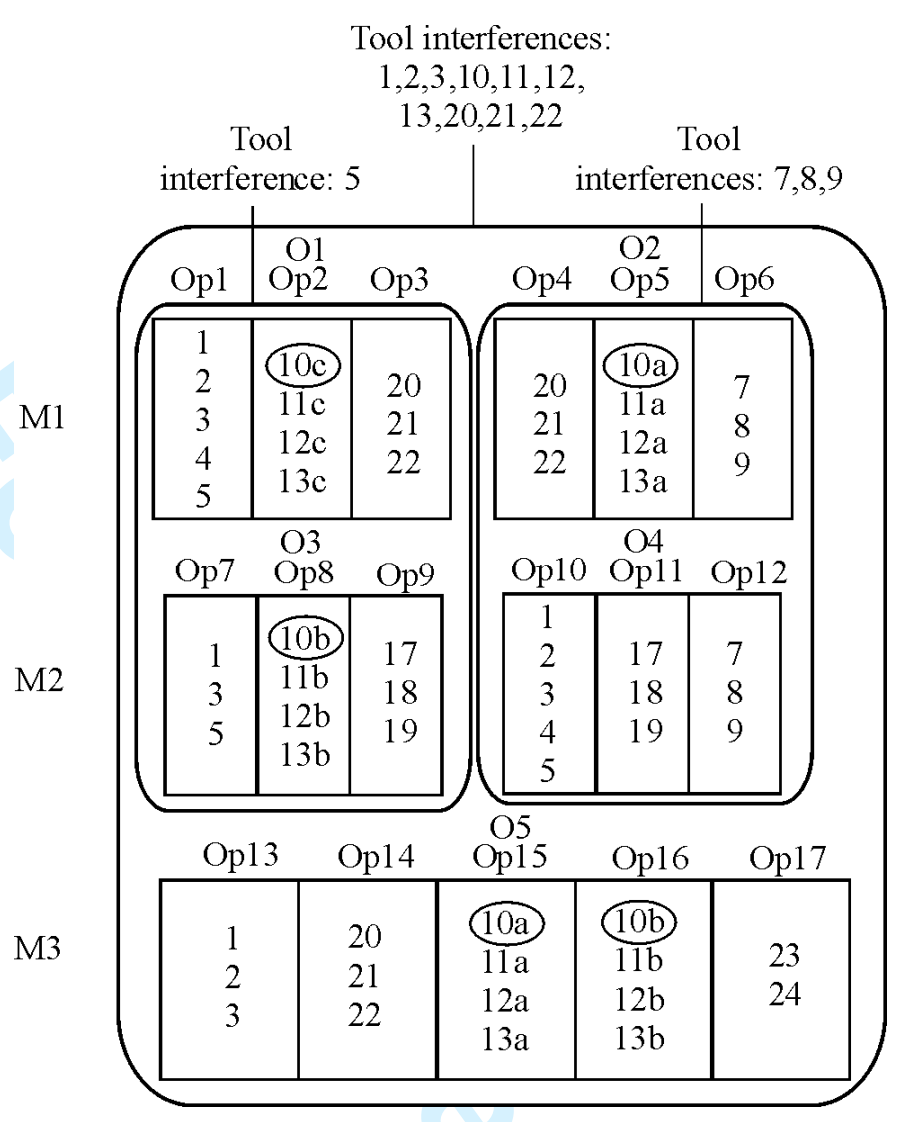

Figure 3. Example of tool interferences 


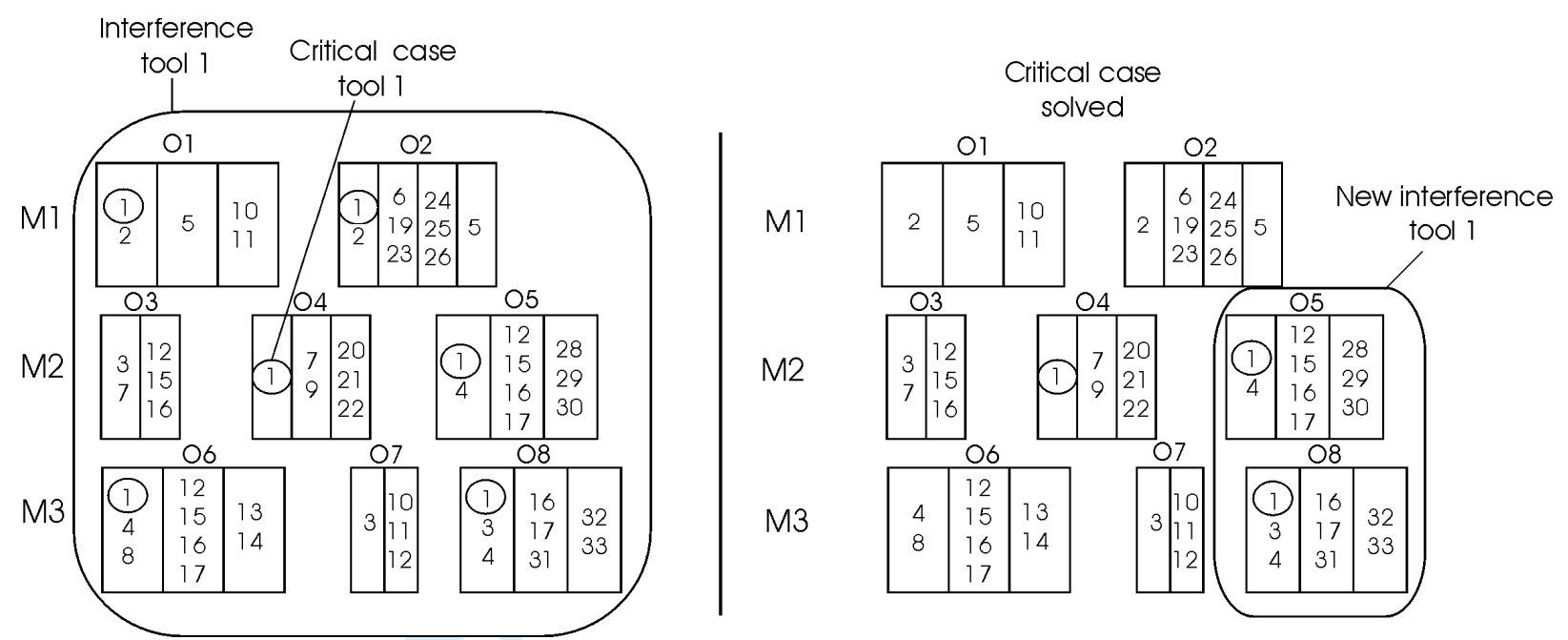

Figure 4. Example of critical case 


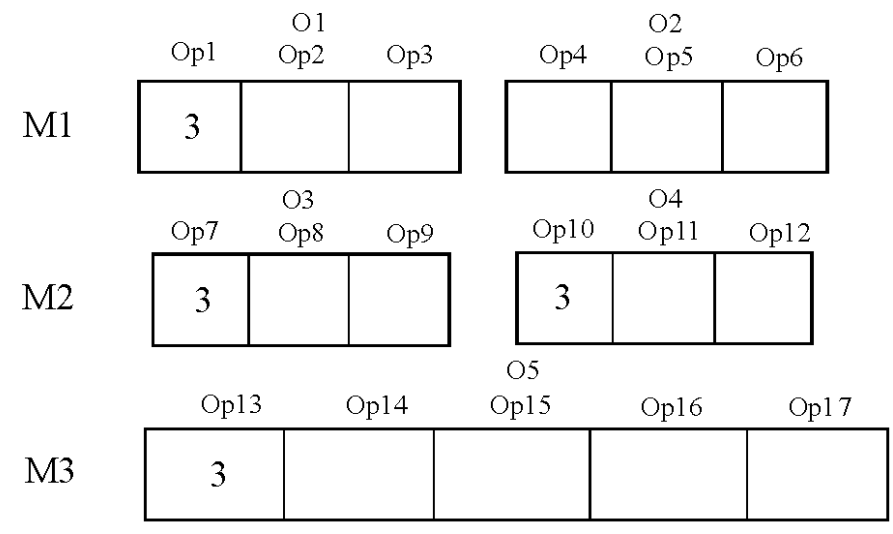

$\begin{array}{cc}\text { Order } & \text { Index A } \\ \text { O1 } & 0 \\ \text { O3 } & 1 \\ \text { O4 } & 0 \\ \text { O5 } & 1\end{array}$

Compatibility Index $\bar{A}$ Transports solutions

$\begin{array}{ccc}\mathrm{O} 1-\mathrm{O} 4 & 0 & 2 \\ \mathrm{O} 3-\mathrm{O} 4 & 1 & 1 \\ \mathrm{O} 5 & 1 & 0\end{array}$

Figure 5. Evaluation of index A and transports 


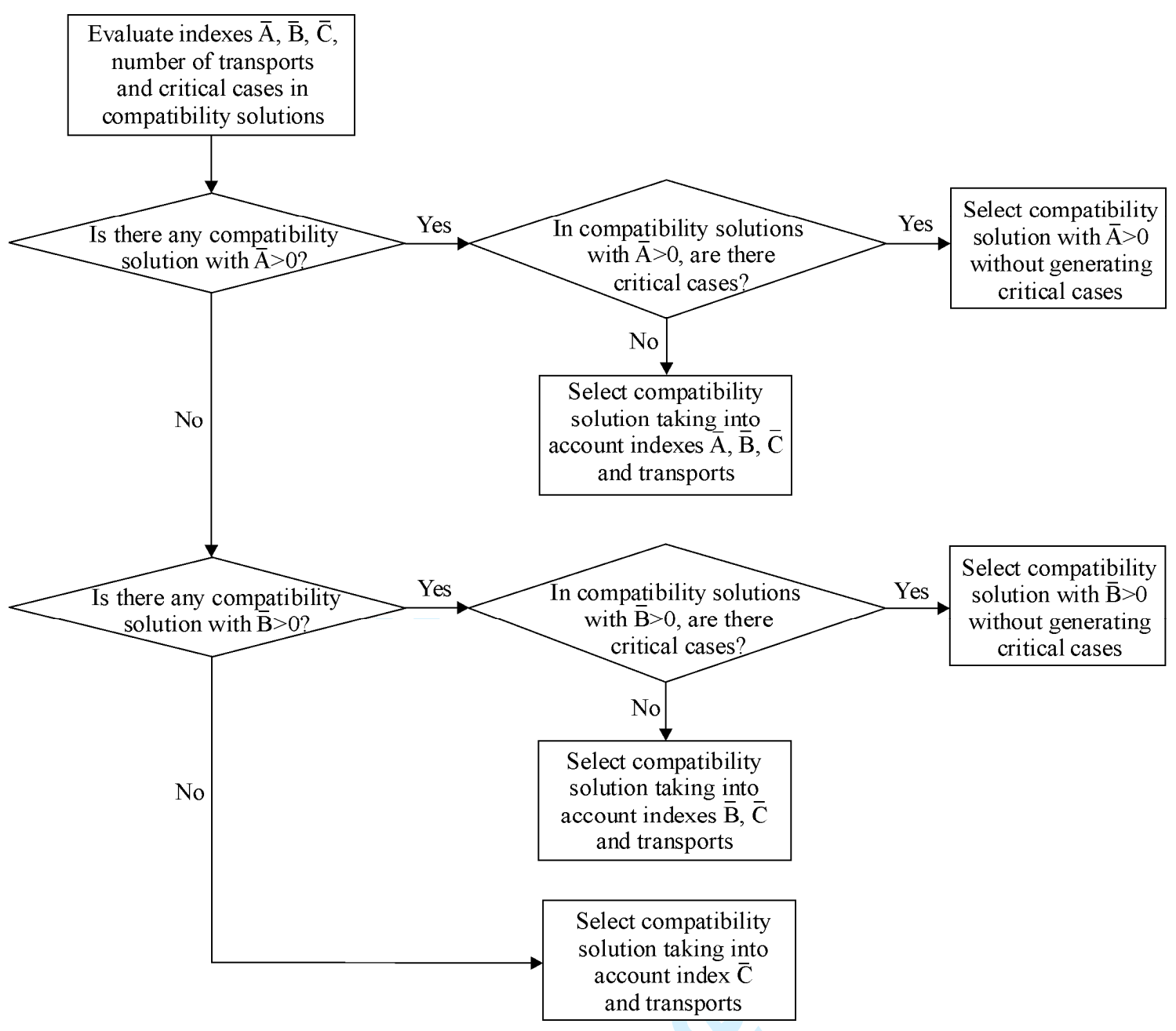

Figure 6. Flow chart for selecting compatibility solution 
M1

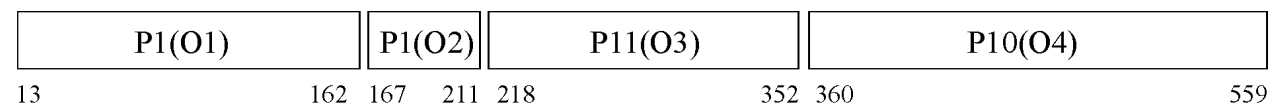

M2

\begin{tabular}{|c|c|c|c|c|}
\hline $\mathrm{P} 13(\mathrm{O} 5)$ & $\mathrm{P} 2(\mathrm{O} 6)$ & $\mathrm{P} 2(\mathrm{O} 7)$ & P7(O8) & P7(O9) \\
\hline
\end{tabular}

M3

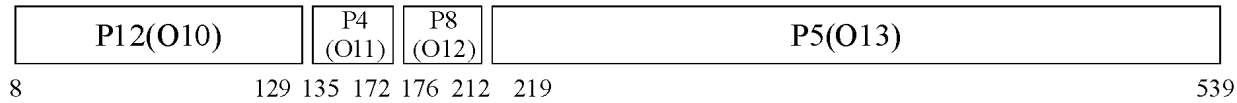

M4

\begin{tabular}{|ll|l|l|l|l|lll|}
\hline $\mathrm{P} 6(\mathrm{O} 14)$ & & $\mathrm{P} 3(\mathrm{O} 15)$ & & $\mathrm{P} 3(\mathrm{O} 16)$ & & $\mathrm{P} 9(\mathrm{O} 17)$ & \\
\hline 5 & 234 & 239 & 320 & 324 & 422428 & & 601
\end{tabular}

Figure 7. Gantt chart of scheduling 
M1

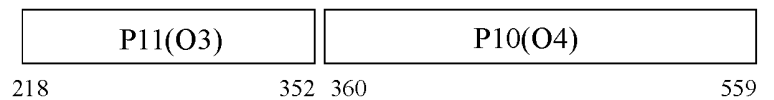

$\begin{array}{lcc}\begin{array}{c}\text { Compatibility } \\ \text { solutions }\end{array} & \text { Index } \overline{\mathrm{A}} & \begin{array}{c}\text { Required } \\ \text { transports }\end{array} \\ \text { O3-O4 } & 2 & 1 \\ \text { O3-O8-O9 } & 3 & 2 \\ \text { O13 } & 1 & 1 \\ \text { O16-08-09 } & 3 & 2 \\ \text { Compatibility } & \text { Index } \overline{\mathrm{B}} & \\ \text { solutions } & & \\ \text { O3-08-09 } & 4 & \\ \text { O16-08-09 } & 3\end{array}$

Figure 8. Compatibility solutions

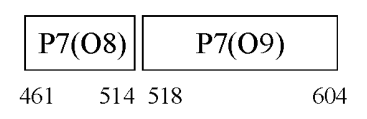

M3

M4

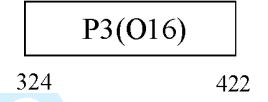


Table 1. Tools description

\begin{tabular}{ccc}
\hline Tool & Type & Diameter \\
\hline 1 & Face mill & 100 \\
2 & Face mill & 80 \\
3 & Face mill & 80 \\
4 & Face mill & 63 \\
5 & Face mill & 63 \\
7 & Indexable end mill & 30 \\
8 & Indexable end mill & 35 \\
9 & Indexable end mill & 40 \\
$10-11-12-13$ & Drill holder & $1-12$ \\
$20-21-22$ & Mill holder & $5-18$
\end{tabular}

19 
Table 2. Operations description

\begin{tabular}{cccc}
\hline Machine & Orders & Operations & Alternative tools \\
\hline M1 & O1 & Face milling (Op 1) & $1-2-3-4-5$ \\
& & Drilling (Op 2) & $10-11-12-13$ \\
& O2 & Profile milling (Op 3) & $20-21-22$ \\
& Profile milling (Op 4) & $20-21-22$ \\
& Drilling (Op 5) & $10-11-12-13$ \\
& & Slot milling (Op 6) & $7-8-9$
\end{tabular}


Table 3. Indexes evaluation

\begin{tabular}{cccccccccccc}
\hline Tool & MRT & MPTM & TC & ANTA & MNTA & I1 & I2 & I3 & I4 & I5 & $\begin{array}{c}\text { Characterization } \\
\text { function }\end{array}$ \\
\hline 1 & 3 & 2 & 2.20 & 4 & 3 & 1 & 1 & 0.65 & 0.75 & 1 & 0.9281 \\
2 & 3 & 1 & 1.93 & 4.3 & 3 & 1 & 0.5 & 0.57 & 0.69 & 1 & 0.8365 \\
3 & 3 & 2 & 2.55 & 4 & 3 & 1 & 1 & 0.76 & 0.75 & 1 & 0.9386 \\
5 & 3 & 2 & 3.35 & 4 & 3 & 0.66 & 0.5 & 1 & 0.75 & 1 & 0.7875 \\
7 & 2 & 1 & 1.55 & 3 & 3 & 0.66 & 0.5 & 0.46 & 1 & 1 & 0.7712 \\
8 & 2 & 1 & 1.70 & 3 & 3 & 0.66 & 0.5 & 0.5 & 1 & 1 & 0.7757 \\
9 & 2 & 1 & 1.80 & 3 & 3 & 0.66 & 0.5 & 0.53 & 1 & 1 & 0.7787 \\
10 & 3 & 2 & 0.92 & 4 & 4 & 1 & 1 & 0.27 & 0.75 & 0.75 & 0.8149 \\
11 & 3 & 2 & 0.92 & 4 & 4 & 1 & 1 & 0.27 & 0.75 & 0.75 & 0.8149 \\
12 & 3 & 2 & 0.92 & 4 & 4 & 1 & 1 & 0.27 & 0.75 & 0.75 & 0.8149 \\
13 & 3 & 2 & 0.92 & 4 & 4 & 1 & 1 & 0.27 & 0.75 & 0.75 & 0.8149 \\
20 & 2 & 2 & 2.36 & 3 & 3 & 0.66 & 1 & 0.7 & 1 & 1 & 0.8706 \\
21 & 2 & 2 & 2.66 & 3 & 3 & 0.66 & 1 & 0.77 & 1 & 1 & 0.8776 \\
22 & 2 & 2 & 2.83 & 3 & 3 & 0.66 & 1 & 0.84 & 1 & 1 & 0.8845
\end{tabular}


Table 4. Tools description

\begin{tabular}{|c|c|c|c|}
\hline Tool & Type & Diameters (mm) & Approach angle \\
\hline 1 & Face mill & 100 & 90 \\
\hline 2 & Face mill & 80 & 90 \\
\hline 3 & Face mill & 80 & 75 \\
\hline 4 & Face mill & 80 & 45 \\
\hline 5 & Face mill & 63 & 90 \\
\hline 6 & Face mill & 63 & 75 \\
\hline 7 & Face mill & 63 & 45 \\
\hline 8 & Face mill & 50 & 90 \\
\hline 9 & Face mill & 45 & 90 \\
\hline 10 & Indexable end mill & 40 & 90 \\
\hline 11 & Indexable end mill & 40 & 75 \\
\hline 12 & Indexable end mill & 40 & 45 \\
\hline 13 & Indexable end mill & 30 & 90 \\
\hline 14 & Indexable end mill & 30 & 75 \\
\hline $15-16$ & Indexable end mill & 20 & 90 \\
\hline 17 & Indexable end mill & 16 & 90 \\
\hline 18 & Indexable end mill & 12 & 90 \\
\hline $19-20-21-22-23-24-25-26$ & Drill holder & $1-12$ & \\
\hline $27-28-29-30$ & Drill holder & $12-18$ & \\
\hline $31-32-33-34$ & Drill holder & $18-24$ & \\
\hline $35-36-37$ & Drill holder & $24-30$ & \\
\hline 38 & Indexable drill & 20 & \\
\hline 39 & Indexable drill & 22 & \\
\hline 40 & Indexable drill & 30 & \\
\hline $41-42-43$ & Boring tool & 40 & \\
\hline $44-45-46$ & Mill holder & $4-6$ & \\
\hline $47-48-49$ & Mill holder & $7-8$ & \\
\hline $50-51-52-53-54$ & Mill holder & $9-10$ & \\
\hline $55-56-57$ & Mill holder & $11-12$ & \\
\hline $58-59-60$ & Mill holder & $13-16$ & \\
\hline $61-62-63$ & Mill holder & $17-20$ & \\
\hline
\end{tabular}


Table 5. Operations and alternative tools

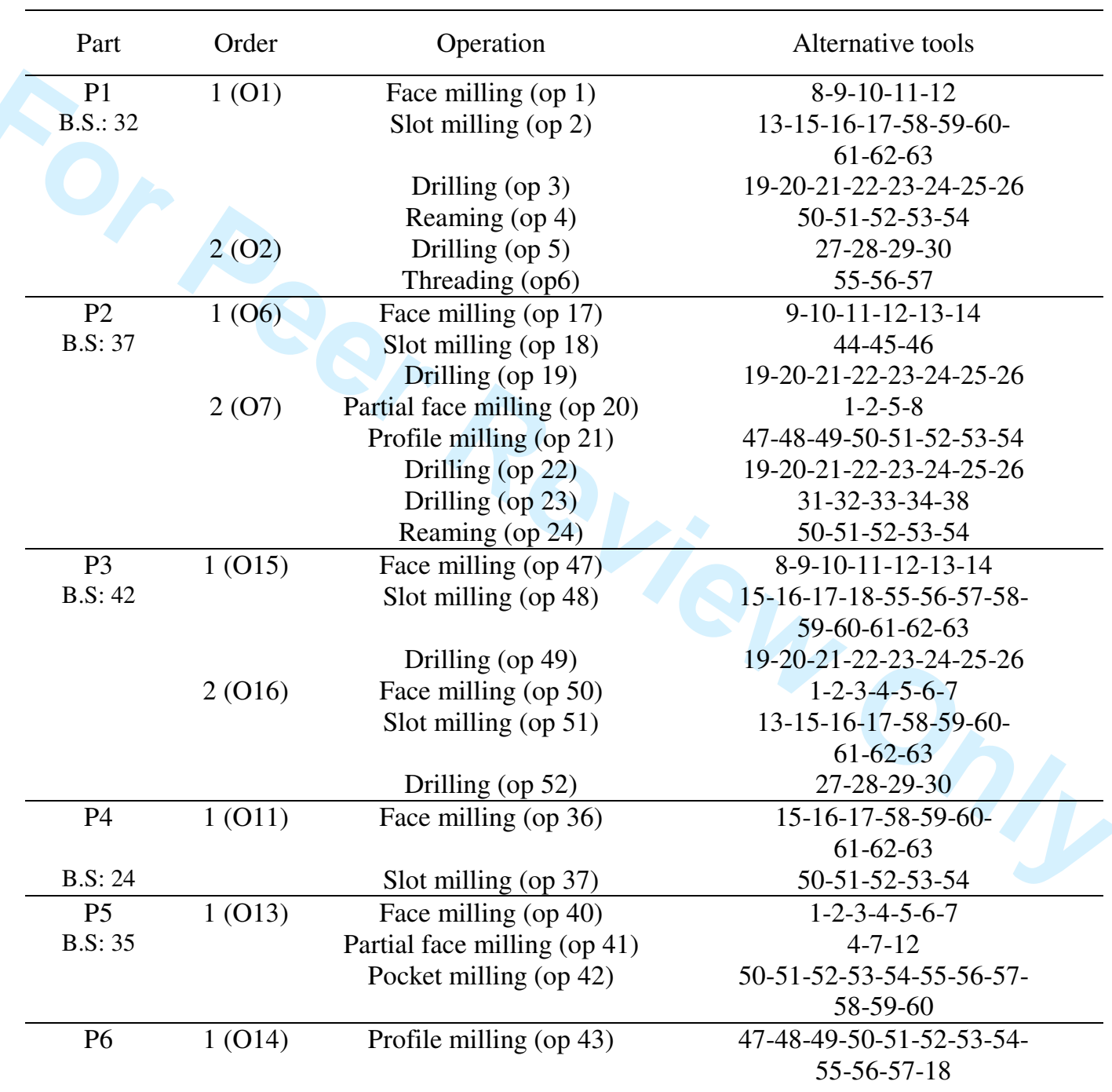

http://mc.manuscriptcentral.com/tprs Email: ijpr@lboro.ac.uk 


\begin{tabular}{|c|c|c|c|}
\hline B.S: 40 & & $\begin{array}{l}\text { Slot milling (op 44) } \\
\text { Pocket milling (op 45) } \\
\text { Drilling (op 46) }\end{array}$ & $\begin{array}{c}50-51-52-53-54 \\
44-45-46-47-48-49 \\
31-32-33-34-39 \\
\end{array}$ \\
\hline \multirow{6}{*}{$\begin{array}{c}\text { P7 } \\
\text { B.S: } 37\end{array}$} & $1(\mathrm{O} 8)$ & Face milling (op 25) & $1-2-3-4-5-6-7$ \\
\hline & & Drilling (op 26) & $19-20-21-22-23-24-25-26$ \\
\hline & & Threading (op 27) & $50-51-52-53-54$ \\
\hline & $2(\mathrm{O} 9)$ & Face milling (op 28) & $1-2-3-4-5-6-7$ \\
\hline & & Drilling (op 29) & $35-36-37-40$ \\
\hline & & Boring (op 30) & $41-42-43$ \\
\hline \multirow{2}{*}{$\begin{array}{c}\text { P8 } \\
\text { B.S: } 30\end{array}$} & $1(\mathrm{O} 12)$ & Drilling (op 38) & $27-28-29-30$ \\
\hline & & Threading (op 39) & $55-56-57$ \\
\hline \multirow{4}{*}{$\begin{array}{c}\text { P9 } \\
\text { B.S: } 34\end{array}$} & 1 (O17) & Partial face milling (op 53) & $8-9-10-13$ \\
\hline & & Profile milling (op 54) & $50-51-52-53-54-55-56-57-18$ \\
\hline & & Slot milling (op 55) & $50-51-52-53-54$ \\
\hline & & Drilling (op 56) & $19-20-21-22-23-24-25-26$ \\
\hline \multirow{3}{*}{$\begin{array}{l}\text { P10 } \\
\text { B.S: } 52\end{array}$} & $1(\mathrm{O} 4)$ & Face milling (op 10) & $1-2-3-4-5-6-7$ \\
\hline & & Drilling (op 11) & $35-36-37-40$ \\
\hline & & Boring (op 12) & $41-42-43$ \\
\hline & $1(\mathrm{O} 3)$ & Face milling (op 7) & $1-2-3-4-5-6-7$ \\
\hline \multirow{2}{*}{ B.S: 42} & & Partial face milling (op 8) & $6-11-14$ \\
\hline & & Pocket milling (op 9) & $\begin{array}{c}50-51-52-53-54-55-56-57- \\
58-59-60-61-62-63\end{array}$ \\
\hline P12 & $1(\mathrm{O} 10)$ & Partial face milling (op 31) & $5-8-9-10$ \\
\hline \multirow[t]{4}{*}{ B.S: 34} & & Partial face milling (op 32) & $4-7-12$ \\
\hline & & Drilling (op 33) & $19-20-21-22-23-24-25-26$ \\
\hline & & Drilling (op 34) & $19-20-21-22-23-24-25-26$ \\
\hline & & Pocket milling (op 35) & $\begin{array}{c}50-51-52-53-54-55-56-57- \\
58-59-60\end{array}$ \\
\hline P13 & $1(\mathrm{O} 5)$ & Profile milling (op 13) & $50-51-52-53-54-55-56-57$ \\
\hline \multirow[t]{3}{*}{ B.S: 27} & & Drilling (op 14) & $19-20-21-22-23-24-25-26$ \\
\hline & & Drilling (op15) & $19-20-21-22-23-24-25-26$ \\
\hline & & Threading (op 16) & $47-48-49$ \\
\hline
\end{tabular}


Table 6. Tool location at the beginning of the working period

\begin{tabular}{cc}
\hline Machine & Tools \\
\hline 1 & $1,5,9,13,17,21,25,29,33,37,41,45,49,53,57,61$ \\
2 & $2,6,10,14,18,22,26,30,34,38,42,46,50,54,58,62$ \\
3 & $3,7,11,15,19,23,27,31,35,39,43,47,51,55,59,63$ \\
4 & $4,8,12,16,20,24,28,32,36,40,44,48,52,56,60$
\end{tabular}


Table 7. Compatible tools

\begin{tabular}{|c|c|c|c|}
\hline Part & Order & Operation & Compatible tools \\
\hline \multirow[t]{6}{*}{$\mathrm{P} 1$} & O1 & 1 & $10-12$ \\
\hline & & 2 & $13-15-16-59-60-61-62$ \\
\hline & & 3 & $21-25$ \\
\hline & & 4 & 52 \\
\hline & $\mathrm{O} 2$ & 5 & $28-29$ \\
\hline & & 6 & 56 \\
\hline \multirow[t]{8}{*}{$\mathrm{P} 2$} & O6 & 17 & $11-14$ \\
\hline & & 18 & 44 \\
\hline & & 19 & $19-22-24$ \\
\hline & $\mathrm{O} 7$ & 20 & 1 \\
\hline & & 21 & $47-48-49-50-53-54$ \\
\hline & & 22 & $19-22-24-26$ \\
\hline & & 23 & $31-32-33-34-38$ \\
\hline & & 24 & 52 \\
\hline \multirow[t]{6}{*}{ P3 } & O15 & 47 & $8-9-10-12-13$ \\
\hline & & 48 & $15-16-17-18-58-60-61-62$ \\
\hline & & 49 & $20-21-23-25$ \\
\hline & O16 & 50 & 2 \\
\hline & & 51 & $13-15-16-17-58-60-61-62$ \\
\hline & & 52 & $27-28-29-30$ \\
\hline \multirow[t]{2}{*}{$\mathrm{P} 4$} & O11 & 36 & $17-58-63$ \\
\hline & & 37 & 50 \\
\hline \multirow[t]{3}{*}{ P5 } & $\mathrm{O} 13$ & 40 & $3-4-5$ \\
\hline & & 41 & 4 \\
\hline & & 42 & $55-57$ \\
\hline \multirow[t]{4}{*}{ P6 } & $\mathrm{O} 14$ & 43 & $18-53$ \\
\hline & & 44 & 51 \\
\hline & & 45 & $45-46-47-49$ \\
\hline & & 46 & $31-32-33-34-39$ \\
\hline \multirow[t]{6}{*}{ P7 } & $\mathrm{O} 8$ & 25 & $1-2-6$ \\
\hline & & 26 & $19-22-24-26$ \\
\hline & & 27 & $50-52-53-54$ \\
\hline & O9 & 28 & $1-2-6$ \\
\hline & & 29 & $36-40$ \\
\hline & & 30 & 42 \\
\hline \multirow[t]{2}{*}{ P8 } & $\mathrm{O} 12$ & 38 & $27-30$ \\
\hline & & 39 & $55-57$ \\
\hline \multirow[t]{4}{*}{ P9 } & O17 & 53 & $8-9-10-13$ \\
\hline & & 54 & $18-56$ \\
\hline & & 55 & 51 \\
\hline & & 56 & $20-21-23-25$ \\
\hline \multirow[t]{3}{*}{ P10 } & O4 & 10 & 7 \\
\hline & & 11 & $35-37$ \\
\hline & & 12 & $41-43$ \\
\hline \multirow[t]{3}{*}{$\mathrm{P} 11$} & $\mathrm{O} 3$ & 7 & $6-7$ \\
\hline & & 8 & 6 \\
\hline & & 9 & $56-59-63$ \\
\hline \multirow[t]{5}{*}{ P12 } & O10 & 31 & $5-8-9$ \\
\hline & & 32 & $4-7$ \\
\hline & & 33 & $23-26$ \\
\hline & & 34 & $19-24$ \\
\hline & & 35 & $50-55-58$ \\
\hline \multirow[t]{4}{*}{ P13 } & O5 & 13 & $54-56-57$ \\
\hline & & 14 & 22 \\
\hline & & 15 & 20 \\
\hline & & 16 & 48 \\
\hline
\end{tabular}


Table 8. Experimental factors

\begin{tabular}{lcc}
\hline Factor & Low level & High level \\
\hline Number of machines & 5 & 8 \\
Number of orders per machine & $\mathrm{UN} \sim[4,6]$ & $\mathrm{UN} \sim[9,11]$ \\
Number of operations per order & $\mathrm{UN} \sim[2,4]$ & $\mathrm{UN} \sim[5,7]$ \\
Tool types & 10 & 20 \\
Number of alternative tools per & $\mathrm{UN} \sim[0.8,1.2]$.number of machines & $\mathrm{UN} \sim[1.8,2.2]$.number of machines \\
operation & &
\end{tabular}


Table 9. Computational times

\begin{tabular}{|c|c|c|c|c|c|c|}
\hline Machines & $\begin{array}{l}\text { Orders } \\
\text { per } \\
\text { machine }\end{array}$ & $\begin{array}{l}\text { Operations } \\
\text { per order }\end{array}$ & $\begin{array}{l}\text { Tool } \\
\text { types }\end{array}$ & $\begin{array}{l}\text { Alternative } \\
\text { tools per } \\
\text { operation }\end{array}$ & $\begin{array}{c}\text { Average } \\
\text { number of } \\
\text { interferences } \\
\text { solved }\end{array}$ & $\begin{array}{l}\text { CPU time } \\
\text { (seconds) }\end{array}$ \\
\hline 5 & Low & Low & Low & Low & 75 & 1.07 \\
\hline 5 & Low & Low & Low & High & 149 & 2.08 \\
\hline 5 & Low & Low & High & Low & 80 & 1.34 \\
\hline 5 & Low & Low & High & High & 177 & 2.89 \\
\hline 5 & Low & High & Low & Low & 81 & 2.61 \\
\hline 5 & Low & High & Low & High & 169 & 4.35 \\
\hline 5 & Low & High & High & Low & 165 & 2.76 \\
\hline 5 & Low & High & High & High & 328 & 5.62 \\
\hline 5 & High & Low & Low & Low & 155 & 3.06 \\
\hline 5 & High & Low & Low & High & 303 & 6.45 \\
\hline 5 & High & Low & High & Low & 145 & 3.51 \\
\hline 5 & High & Low & High & High & 312 & 9.05 \\
\hline 5 & High & High & Low & Low & 163 & 6.46 \\
\hline 5 & High & High & Low & High & 335 & 14.81 \\
\hline 5 & High & High & High & Low & 285 & 6.08 \\
\hline 5 & High & High & High & High & 563 & 15.63 \\
\hline 8 & Low & Low & Low & Low & 118 & 2.72 \\
\hline 8 & Low & Low & Low & High & 222 & 6.48 \\
\hline 8 & Low & Low & High & Low & 183 & 3.78 \\
\hline 8 & Low & Low & High & High & 356 & 6.48 \\
\hline 8 & Low & High & Low & Low & 192 & 6.07 \\
\hline 8 & Low & High & Low & High & 377 & 11.92 \\
\hline 8 & Low & High & High & Low & 348 & 7.35 \\
\hline 8 & Low & High & High & High & 515 & 12.96 \\
\hline 8 & High & Low & Low & Low & 224 & 7.87 \\
\hline 8 & High & Low & Low & High & 412 & 20.81 \\
\hline 8 & High & Low & High & Low & 328 & 8.10 \\
\hline 8 & High & Low & High & High & 617 & 23.61 \\
\hline 8 & High & High & Low & Low & 333 & 17.22 \\
\hline 8 & High & High & Low & High & 641 & 44.66 \\
\hline 8 & High & High & High & Low & 359 & 16.35 \\
\hline 8 & High & High & High & High & 754 & 40.46 \\
\hline
\end{tabular}

